\title{
Research on the Aesthetic Generality of Modern Art and Interior Design Xudong $\operatorname{Jin}^{1, \text { a }}$ \\ ${ }^{1}$ Nanjing Institute of Railway Technology, Nanjing, Jiangsu, China, 210031 \\ aemail
}

Keywords: Aesthetic Generality, Modern Art, Interior Design

\begin{abstract}
The aesthetics law of architecture and interior design is from the development of abstract art, initiated by Cubism and Futurism, after exploring the many artists, forming a great value for the rule of aesthetics of interior design. Modern art in pursuit of fashion and trends, modern art interior design also is the pursuit of fashion and trends, which attaches great importance to the overall layout of the interior space, but also pays attention to the perfect combination of interior space and the use of functional layout. Interiors follow certain aesthetic principles, but also contains modern art thinking.
\end{abstract}

\section{The Concept of Interior Design}

Simply put, the overall design of the indoor environment is the concept of interior design, which includes indoor and outdoor space constitution design environmental design, indoor environmental systems, environmental design decorative furnishings and interior decoration technology design. The interior design is also known as interior design and interior decoration, saying there are differences in substance is the same, which mainly includes the combination of the two-room flat and content space for the whole interior layout, interior surface treatment of art home furnishings and interior styling and layout style, this article focuses on this part of space.

\section{The Aesthetic Characteristics of Interior Design}

The "Simple" Nature of Interior Design. With the progress and development of society, and the pursuit of human needs are also changing. In today's increasingly complex social context, people are more willing to abandon luxury abandon grandiose, turn to the pursuit of simple, minimalist forms and people for the pursuit of more and more intense. This phenomenon is also reflected in the results of the interior designer design, this performance is the natural pursuit of minimalist style, which makes raw materials and technical requirements more stringent, such as a modern, more to promote the use of new materials, new technologies to design the indoor environment, the theme is simple and easy to understand and pay attention to the modern interior of use. In addition, the indoor home decoration is a certain stress, everything must be disposed of in accordance with the principles of indoor function to be differentiated, furniture, furnishings should be closely linked to the existing space, closely cooperate in color, more fashion elements color, but also to abandon the extra modification, in order to avoid cumbersome.

The "Green" Nature of Interior Design. Contemporary society, the concept of environmental protection has gained more and more attention people pay attention to the surrounding environment, so people are very particular about the indoor environment, promote green design. This green design is no pollution, no pollution design. Of course, contamination and pollution here referred not only in the traditional sense, in addition to the direct dangers of pollution, including visual pollution, light pollution and even space pollution, this pollution cannot be reflected in the design of modern green, otherwise it cannot be termed designed to be environment-friendly. It will start from the environmentally friendly green interior design concept of thinking into which this type of life and build environmentally friendly green philosophy is consistent.

The "Meaning" of Interior Design. With respect to the past, in the treatment of interior design, people pay more attention to beauty of form. This is due to current social and living conditions of the decision, because people pay more attention to spiritual pursuits, which manifested in interior 
design, as well as deepening the practice, people's aesthetic consciousness of this concept has also undergone a fundamental change, people for aesthetic pursuit steering profound cultural awareness from a single form for the pursuit of artistic style and a sense of aesthetic changes are reflected in the interior design style, modern interior designer or homeowner often expressed the idea and value pursuit, it has profound meaning.

The "Nature" of Interior Design. In ancient times, we have had only lived in the property houses the era, in addition to housing for modern people live and there is the aesthetic enjoyment, it is an object of modern interior design is to build an environmentally friendly, healthy, and enjoy living space . For people living space requires a qualitative change still occurs. People want to give their designers can continue to build a space to provide their own nutrition, nature can absorb nutrients, to enrich themselves and enrich their lives

\section{The Aesthetic Blend Principles of Modern Art and Interior Design}

Integrated Principles. Integrity principle states that all objects indoor area by an object or element as a hub to connect, in this process, the correlation between the object, then the formation of a basic commonality, and eventually will form a whole toward reunification.

People-Oriented Principle. People-oriented is the basic principle of interior design. People-oriented principle requires that the interior design must always put people first, user-centered. Adhere to the people-oriented principle, which requires designers to fully listen to the requirements of the owner, as well as emotional appeals to the modern aesthetic requirements as a benchmark for innovative design on this basis. Designers need to take into account all factors, including lifestyle, life experience, habits, aesthetic requirements, etc., each person interior design requirements are not the same, only the designer to understand and contrast, and then come up with a overall design, so as to better meet consumer demand for the pursuit of living space.

Unity Principle. The fundamental purpose is to give people the interior design to create an ideal place to live, people often seek a comfortable life of leisure environment, but also the pursuit of modern high-tech brings enjoyment in the form of expression to give people a beautiful experience. According to these, the designer in interior design must take into account the unity of form and function, functional beauty and sense of form combine to create an ideal place for people to live, so the design, not because of the simple form to pursue art or is a certain level of technology and overall unity.

Ecological Principles. Ecological principle refers to respect nature and conserve resources. Advocating human harmony with nature today, the interior is bound to respect nature, be sure to correctly deal with the relationship between the designer interior design and the environment, the natural environment of the control must be strict. To use non-polluting, recyclable materials, avoid harmless, and eliminate excessive packaging design, excessive luxury and so avoid excessive waste of resources, and promote the scientific conservation-oriented design approach and lifestyle. Furthermore, the interior design should be adapted to local conditions, according to the geographical environment and climatic conditions, the development of scientific design. Before such as interior designers to design, to investigate the local geography and climate conditions, adopt a scientific design, reasonable use of the advantages of the local climate or geographical advantages, so as to avoid unnecessary waste.

\section{The Aesthetics Common Realization of Modern Art and Interior Design}

The Integrated Design of Furniture and Interior. Relative to other factors, furniture for interior design is also very important, because the main furniture is composed of indoor space. On the choice of furniture and how to arrange the problem, it is particularly important because it relates to the overall interior design style. It has been mentioned earlier the whole idea that when "the overall for the United States" is to achieve overall unity indoor environment and furniture layout, so that the overall unity, it requires the designer during the room layout of the interior design and decoration to make good planning, the overall shape and style of furniture to sort out plan, to make 
furniture and interior style to achieve fusion, the overall layout of the room has the unity, the formation of integrated design.

Interior design is often restricted space interface, because the interface is a certain space, so often leads to spatial features are not very good play. This time the furniture is the best supplement, you can use the function of the furniture to make up for limited space interface defects. According to the designer to plan the size of the space in which the furniture size, shape, color and so on. Thus, the interior and furniture perfect match on the entire interior design to achieve overall optimization. In addition, the design is also very particular about the furniture, the designer for the design of furniture is often using a variety of module, it is easy to form various adjustments with various forms of furniture, so that you can adapt to the needs of space, furniture and indoor environment complement each other, so that the integration of furniture and interior, which not only meet the aesthetic needs of the people, but also reflects the traditional heritage of philosophy of aesthetics.

Create a Whole Atmosphere. Create the overall mood of the room, refers to a mix of interior space, materials, colors, ambience, shape and other factors, these factors to achieve the perfect unity of mood. With the overall sense of space, because all aspects of the various elements of the interior must be unified, space and the interdependence of the various elements of influence, thus achieving harmony of spatial form. To create the overall atmosphere of the indoor environment, the designer will feel the space where the soul, seeks to locate and design elements with Chinese characteristics and the local style, then it will be integrated into the interior decoration and furniture being so, space, furniture, decoration and other elements to achieve harmony in the visual on people of a certain aesthetic impact. Factors for people of color, is a very impactful color for the living environment is also a very important factor. Comfortable, aesthetic indoor environment can always gives a harmonious feeling because the atmosphere can color the indoor environment is very concrete images to contrast it.

On the material selection and matching, but it needs careful. Interior decoration materials to be used to select the actual situation, because different materials have different textures, used in the decoration they give rise to different experiences and feelings, so the choice of material to be removed from the appropriate visual and tactile aspects consider that this is one of the most basic needs of the point, at the same time different ages, different personalities, different people to choose the gender of the indoor environment will be different, the choice of color of the material will vary, but also according to their preferences to choose.

The Injection of Ecological Element. Due to the deterioration of the natural environment, people issues are increasingly concerned about the ecological environment, ecological always cherished a complex, therefore, it is for their own living environment also hope the injection environment. Currently, for the designer, ecological concept has been printed in my mind, is the eco-design designers strive for the direction, of course, in China since ancient times, the concept of ecology, "Heaven" concept existed since ancient times, people live in harmony with the admission's ideas into the living space design. On the other hand, the ecological significance is narrowly understood, some people think the aisle plant a few trees, built rockery leave the water or the construction of a canal would be tantamount to ecological, this is actually a very superficial understanding, even worse, One might therefore into destroying the ecology of errors, such as home decoration with the original wood, which is wood demand is huge, the number of forest resources takes, this is a violation of a fundamental ecological principle, and is contrary to our original intention. Indoor environment designed to fundamental ecological, build a green, healthy and harmonious space environment.

According to statistics, often appear to indoor air pollution is more serious than outdoor air conditions, the survey shows that the furniture and interior decoration materials, two factors are the main cause of pollution in furniture and decorative materials is inappropriate selection cause serious pollution, the frightening thing is that the surrounding environment pollution will have some impact, the vicious circle, the ultimate victims or our own. Therefore, the choice of furniture and interior decoration materials is sure to choose green materials.

The sun is the most common and most important resource, solar energy for humans, 
environmentally friendly and practical, so if the housing is designed to make full use of solar resources, lighting, heat, etc. to design a scientific and rational housing design, the designer should full use of solar resources, so that each room lighting conditions are good, according to local geographical conditions, rational planning. In the design, to mobilize all the technical feasibility, may be cut off as a way to increase spatial light transmission, and then use glass installation, through the skylight to absorb sunlight, if necessary, Ming Room, bright kitchen, Ming Wei and other design use, so make full use of solar energy, environmentally friendly and healthy.

In the choice of materials, to make use of new environmentally friendly materials, while the use of high technology, a combination of both, in a prominent close to nature close to the original ecology at the same time, but also a high technology integration, so that not only embodies the concept of environmental protection, but also charge now projecting a modern style. The new material, then you can consider using a high density in an environmentally responsible materials, and plastics and resins are also a good environmental choice, such a contrast to the traditional wood trim can save a lot of trees, which coincided with the contemporary pursuit of environmental protection concepts coincide, but also it reflects the minimalist simple aesthetic needs.

Ancient house, especially garden design rockery fake water is a very common design, designers have ancient references to its interior design, is actually a "borrowed landscape" method of use. In ancient times, designers can Ancient Landscapes "by King" cleverly applied to the design of the indoor environment, for example, through the clever idea of the "Garden Landscape" scenes into the room, careful layout on both sides of the water, Add Stone Forest, trees, flowers, etc., extremely delicate, had Fu Zhang praised.

Designers as well as "its essence" in the traditional residential design focus a little can be learned to use, and innovation. For example, in traditional design, interior space division method is a good point, designers can take advantage and innovation, screens, sliding door and use drop cloths may be formed separated and continuous flow of forms, the interior layout more close to nature and fresh, so inspired, modern design, you can also use the curtain or bamboo and other ways to partition dividing the interior space, and "every other constantly vivid effect.

Increasingly focused on the pursuit of modern artistic conception, the living space is also attached great importance to the pursuit of artistic conception, "virtual" and "real" depiction of modern living space through interior elements to shape, is through indoor furniture, decorative materials and lighting and other elements to the performance of "virtual" and "real" design, and flexibility into every step of the design, which makes the living space to enjoy with a poetic form relaxed aesthetic taste. Designer for "virtual" and "real" to grasp is the modern interior design aesthetic pursuit.

\section{Conclusion}

Continuous development of society, the continuous material abundance, people are increasingly seeking spiritual enrichment, it is for the interior design of the aesthetic value of the pursuit of higher and higher, the essence of traditional and modern aesthetics into modern living spaces designed to form an irresistible integration of new ideas on the wave of color in interior design, space and other factors, the designer of the design concept has been further developed.

\section{References}

[1] Huifang Zhou: Contemporary Design, Vol. 6 (2004) No 53, p.25-26

[2] Hongli Zhang: Trendy Household, Vol. 12 (2005) No 27, p.74-76

[3] Qin Guo: Elle Decoration, Vol. 1 (2006) No 33, p.11-14

[4] Jieming Liu: Guangxi Normal University, Vol. 3 (2007) No33, p.121-124

[5] Wang Bing: Elle Decoration, Vol. 1 (2012) No 13, p.56-60 